\title{
Comparative Study of the Clinical Features and Treatment for Right and Left Colonic Diverticulitis
}

\author{
Seok Hoon Kim, Chang Gyoo Byun, Jin Woo Cha, Seok Ho Choi, Young Taek Kho, Dong Yup Seo \\ Department of Surgery, National Police Hospital, Seoul, Korea
}

Purpose: Colonic diverticulitis is an uncommon disease in Korea, but the incidence of the disease is increasing. The right colon is the more preferred site for diverticulitis in Korea, but the incidence of left diverticulitis is increasing. Therefore, comparing the clinical features and treatments for right diverticulitis with those for left diverticulitis may help us to treat the disease more properly.

Methods: This study was performed retrospectively by reviewing the medical records of 96 patients with colonic diverticulitis, in whom either conservative or operative treatments were performed.

Results: Eighty-six patients had right diverticulitis (RD), and 10 patients had left diverticulitis (LD). The mean age of the patients was older for LD. Sixteen patients (18.6\%) with RD had complications, and 7 patients (8.1\%) underwent operations. On the other hand, 4 patients (40\%) with LD had complications, and 3 patients $(30 \%)$ underwent operations. The rates of complications and operations among old-aged patients were higher. The operations for 7 patients with $\mathrm{RD}$ who underwent surgery were 6 ileocecectomies and 1 diverticulectomy. On the other hand, the operations for the 3 patients with LD who underwent surgery were 2 resections and anastomoses and 1 diverticulectomy. The reasons for the operations were abscess formation, recurrence, perforation, and development of generalized peritonitis without response to conservative treatment.

Conclusion: The incidence of LD is lower than that of RD in Korea, but the rate of complications and operations seems higher in LD. Therefore, patients who complain of left lower abdominal pain need to be thoroughly examined for LD.

\section{Keywords: Colon; Diverticulitis}

\section{INTRODUCTION}

Colonic diverticular disease is known to be a common disease in Caucasians, but to be relatively rare in Asians [1]. Nevertheless, due to recent improvements in diagnostic methods, increases in the geriatric population, and westernization of diet, the incidence of colonic diverticular disease in Asians, includ-

Received: August 3, 2010 Accepted: October 15, 2010

Correspondence to: Chang Kyu Byun, Ph.D.

Department of Surgery, National Police Hospital, Garakbon-dong,

Songpa-gu, Seoul 138-708, Korea

Tel: +82-2-3400-1237, Fax: +82-2-431-2395

E-mail: primeroses@naver.com

(C) 2010 The Korean Society of Coloproctology

This is an open-access article distributed under the terms of the Creative Commons Attribution NonCommercial License (http://creativecommons.org/licenses/by-nc/3.0) which permits unrestricted noncommercial use, distribution, and reproduction in any medium, provided the original work is properly cited ing the Koreans, has been shown to be on the rise. In Caucasians, colonic diverticular disease occurs preferentially in the left colon, particularly, in the sigmoid colon, while in Asians, it occurs preferentially in the right colon, including the cecum. According to a retrospective study performed in Korea on 12,599 patients who underwent barium enemas, colonic diverticular disease in the right colon is 6 times more prevalent than it is in the left colon [2]. In Caucasians, acquired false diverticula have been shown to be prevalent, while in Asians, congenital true diverticula are prevalent, and this occurs at ages 10-20 years younger than it does in Caucasians [3-5]. Colonic diverticular disease has been reported to be asymptomatic in most cases, and symptomatic cases account for $10 \%$ to $20 \%$ of all patients. In Caucasians, it occurs prevalently in the left colon. In Asians, it occurs prevalently in the right colon $[2,6,7]$.

Patients with colonic diverticular disease without complications respond well to nonsurgical antibiotic treatments. How- 
ever, if it recurs frequently or is associated with abscess, obstruction, fistula formation and other complications, surgical treatments are required [8]. In the West where the focus is on treatment for left colonic diverticular disease, a proximal colostomy and a 2-stage colectomy were suggested a long time ago. Since then, with the development of antibiotics, surgery has not been performed on all diverticular disease patients, and studies of surgical treatments, such as elective surgery after percutaneous drainage only, on cases associated with complications, primary anastomosis after intestinal irrigation during surgery, or laparoscopic surgery, have been reported [9]. In comparison, studies conducted in Korea on surgical treatments for diverticulitis with complications have focused mainly on right colonic diverticulitis, so reports vary from only a simple diverticulectomy and appendectomy to a colectomy. Reports on left colonic diverticulitis are rare. Therefore, in our study, the difference in clinical features, depending on the location of diverticulitis and the treatment method, were examined.

\section{METHODS}

A retrospective study was performed on 96 patients diagnosed as having colonic diverticulitis at the Department of Surgery, National Police Hospital, from January 2007 to December 2009 by analyzing their medical record. For the 96 patients, the age of patients, gender, lesion site, early symptoms, status of complications, and status of surgery were analyzed. Of the 96 patients, 88 patients were diagnosed by using abdominal CT, 5 patients were diagnosed after surgery for appendicitis that had been erroneously diagnosed by using abdominal ultrasonography but really was cecal diverticulitis, and 3 patients were diagnosed by using abdominal ultrasonography. For the 5 cecal diverticulitis patients erroneously diagnosed as having appendicitis, only an appendectomy was done and subsequently conservative treatment was performed. Since the operations were not for diverticulitis, they were not included in the statistical analysis of surgery for diverticulitis itself.

Diverticulitis distributed in the cecum, the ascending colon, and the hepatic flexure was classified as right colonic diverticulitis (RD). Diverticulitis in the descending colon and the sigmoid colon was classified as left colonic diverticulitis (LD). In our study, indications for surgery were perforation associated with generalized peritonitis, abscess formation, diverticulitis that had recurred more than 3 times in 2 years, and cases that were unresponsive to conventional treatments and had progressed to peritonitis.

For the statistical analysis of factors that effects the selection of treatment methods, the chi-square test and the Mann-Whitney test were performed by applying the SPPS ver. 12.0 (SPSS Inc., Chicago, IL, USA). P-values less than 0.05 were considered to be significant.

\section{RESULTS}

\section{Characteristics of the patients and distribution of diverticulitis}

RD patients were 86 cases, and LD patients were 10 cases. The ratio of $\mathrm{RD}$ to $\mathrm{LD}$ was $8.6: 1$, and $\mathrm{RD}$ patients were noticeably more abundant. Among the $86 \mathrm{RD}$ patients, 56 patients developed diverticulitis in the cecum, 29 patients in the ascending colon, and 1 patient in the hepatic flexure. Among the $10 \mathrm{LD}$ patients, 8 patients developed diverticulitis in the sigmoid colon, and 2 patients in the descending colon. Among the $86 \mathrm{RD}$ patients, 52 patients were males, 34 patients were females, and the ratio of males to females was 1.53:1. The mean age was 39.5 years (range, 16 to 69 years). Among the $10 \mathrm{LD}$ patients, 6 patients were males, 4 patients were females, and the ratio of males to females was 1.5:1. The mean age was 52.5 years (range, 38 to 70 years), and LD developed at an older age $(\mathrm{P}<0.001)$ (Table 1$)$.

\section{Clinical characteristics of diverticulitis}

The most frequent symptom of colonic diverticulitis was abdominal pain. Other frequent symptoms after abdominal pain were leucocytosis, fever, nausea, vomiting, and changes in bowel habits. Although rare, a mass was palpated in some cases. Particularly, the incidence of surgery for patients with abdominal rigidity or palpable masses was high. The symptomatic duration from the onset of abdominal pain to hospital visit for the right colonic diverticulitis patient was an average 2.5 days, and that for left colonic diverticulitis patients was an average 2.1 days (Table 2).

Among the $86 \mathrm{RD}$ patients, 16 patients were associated with complications. Among them, in 11 patients, the complication was recurrence more than 2 times, in 4 patients, it was abscess formation, and in 1 patient, it was unresponsiveness to conservative treatments and progression to peritonitis. In addition, among the $16 \mathrm{RD}$ patients associated with complications, surgery was performed on 7 patients- 4 patients with abscess formation, 2 patients with more than 3 instances of repeated di-

Table 1. Age \& sex distribution of the patients

\begin{tabular}{lccc}
\hline & $\mathrm{RD}(\mathrm{n}=86)$ & $\mathrm{LD}(\mathrm{n}=10)$ & P-value \\
\hline $\begin{array}{l}\text { Male:Female } \\
\text { Age }\end{array}$ & $52: 34$ & $6: 4$ & 0.977 \\
$\quad$ & & \\
Median (range) & $39.5(16-69)$ & $52.5(38-70)$ & $<0.001$ \\
Distribution & & & \\
$<30$ & $24(27.9)$ & $0(0)$ & \\
$30-39$ & $19(22.1)$ & $1(10)$ & \\
$40-49$ & $32(37.2)$ & $3(30)$ & \\
$50-59$ & $7(8.1)$ & $3(30)$ & \\
$\geq 60$ & $4(4.7)$ & $3(30)$ & \\
\hline
\end{tabular}

Numbers in parentheses are percentage.

$\mathrm{RD}$, right colonic diverticulitis; $\mathrm{LD}$, left colonic diverticulitis. 
verticulitis in 2 years, and 1 patient unresponsive to conservative treatments with progression to peritonitis. On the other hand, among the $10 \mathrm{LD}$ patients, 4 patients developed complications of diverticulitis. Among them, in 2 patients, the complication was perforation associated with generalized peritonitis, in 1 patient, it was unresponsiveness to conservative treatments and progression to peritonitis, and in 1 patient, it was

Table 2. Symptoms and signs

\begin{tabular}{|c|c|c|c|}
\hline & $\mathrm{CT}(\mathrm{n}=79)$ & ST $(n=7)$ & P-value \\
\hline \multicolumn{4}{|l|}{$\mathrm{RD}$} \\
\hline Symptom duration (day) & 2.44 & 3.14 & \\
\hline Abdominal pain & $74(93.7)$ & $7(100.0)$ & 1.000 \\
\hline Fever $\left(\geq 38.0^{\circ} \mathrm{C}\right)$ & $26(32.9)$ & $4(57.1)$ & 0.232 \\
\hline Leukocytosis $\left(\geq 10,000 / \mathrm{mm}^{2}\right)$ & $55(69.6)$ & $6(85.7)$ & 0.688 \\
\hline Nausea or vomiting & $18(22.8)$ & $3(42.9)$ & 0.354 \\
\hline Diarrhea & $15(18.9)$ & $3(42.9)$ & 0.156 \\
\hline Constipation & $5(6.3)$ & $1(14.3)$ & 0.409 \\
\hline Abdominal wall rigidity & $1(1.3)$ & $4(57.1)$ & $<0.001$ \\
\hline \multirow[t]{2}{*}{ Palpable mass } & $4(5.1)$ & $4(57.1)$ & $<0.001$ \\
\hline & CT $(n=7)$ & ST $(n=3)$ & P-value \\
\hline \multicolumn{4}{|l|}{ LD } \\
\hline Symptom duration (day) & 2.14 & 2.00 & \\
\hline Abdominal pain & $7(100.0)$ & $3(100.0)$ & a \\
\hline Fever $\left(\geq 38.0^{\circ} \mathrm{C}\right)$ & $2(28.6)$ & $2(66.7)$ & 0.500 \\
\hline Leukocytosis $\left(\geq 10,000 / \mathrm{mm}^{2}\right)$ & $5(71.4)$ & $3(100.0)$ & 1.000 \\
\hline Nausea or vomiting & $1(14.3)$ & $1(33.3)$ & 1.000 \\
\hline Diarrhea & 2 (28.6) & $0(0.0)$ & 1.000 \\
\hline Constipation & $1(14.3)$ & $1(33.3)$ & 1.000 \\
\hline Abdominal wall rigidity & $0(0.0)$ & $3(100.0)$ & a \\
\hline Palpable mass & $1(14.3)$ & $0(0.0)$ & a \\
\hline
\end{tabular}

Numbers in parentheses are percentages.

$\mathrm{CT}$, conservative treatment; ST, surgical treatment; RD, right colonic diverticulitis; $L D$, left colonic diverticulitis.

${ }^{a}$ No statistics are computed.

Table 3. Causes for surgical treatment in patients with colonic diverticulitis

\begin{tabular}{lcc}
\hline & $\mathrm{RD}(\mathrm{n}=7)$ & $\mathrm{LD}(\mathrm{n}=3)$ \\
\hline $\begin{array}{l}\text { Developing to generalized peritonitis } \\
\text { without response to conservative } \\
\text { treatment }\end{array}$ & $1(14.3)$ & $1(33.3)$ \\
Recurrence ( $\geq 3$ times) & $2(28.6)$ & $0(0.0)$ \\
Abscess formation & $4(57.1)$ & $0(0.0)$ \\
Perforation & $0(0.0)$ & $2(66.6)$ \\
\hline
\end{tabular}

Values are presented as number (\%).

$\mathrm{RD}$, right colonic diverticulitis; $\mathrm{LD}$, left colonic diverticulitis. two recurrences. In addition, among the $4 \mathrm{LD}$ patients associated with complications, surgery was performed on 3 patients2 patients with perforation associated with general peritonitis, and 1 patient unresponsive to conservative treatments and showing progression to peritonitis (Table 3 ).

In $\mathrm{RD}$ patients, 16 patients (18.6\%) were associated with complications, and in LD patients, 4 patients (40\%) were associated with complications. Although the incidence of complications was higher in $\mathrm{LD}$ than in $\mathrm{RD}$, this difference was not statistically significant $(\mathrm{P}=0.115)$. On the other hand, for $\mathrm{RD}$ patients, $7(8.1 \%)$ were associated with complications requiring surgery while for LD patients, that number was 3 (30\%). In comparison with $\mathrm{RD}$, the frequency of complications requiring surgical treatments was higher in LD patients $(P=0.032)$. In addition, the incidence of complications requiring surgery was higher in older patients, but this difference was not statistically significant $(\mathrm{P}=$ 0.065). No correlation of gender to the incidence of complications requiring surgery was observed (Table 4).

\section{Conservative treatments}

Seventy-nine RD patients and $7 \mathrm{LD}$ patients were improved by conservative treatments. Conservative treatments were fasting with intravenous fluid being administered until the amelioration of abdominal pain and antibiotic injection. The mean hospitalization period to discharge was 5.31 days, and after discharge, oral antibiotics were administered for an additional 7 days.

Table 4. Patient characteristics according to treatment method

\begin{tabular}{lrcc}
\hline & CT $(n=86)$ & ST $(n=10)$ & P-value \\
\hline Age & & & \\
-40 & $43(93.5)$ & $3(6.5)$ & 0.065 \\
$41-60$ & $40(88.9)$ & $5(11.1)$ & \\
$61-$ & $3(60.0)$ & $2(40.0)$ & \\
Gender & & & \\
$\quad$ Male & $53(91.4)$ & $5(8.6)$ & 0.477 \\
Female & $33(86.8)$ & $5(13.2)$ & \\
Location & & & \\
Right & $79(91.9)$ & $7(8.1)$ & 0.032 \\
Left & $7(70.0)$ & $3(30.0)$ & \\
\hline
\end{tabular}

Values are presented as number (\%).

$\mathrm{CT}$, conservative treatment; $\mathrm{ST}$, surgical treatment; $\mathrm{RD}$, right colonic diverticulitis; $\mathrm{LD}$, left colonic diverticulitis.

Table 5. Method of operation

\begin{tabular}{ll}
\hline Operation & No. \\
\hline Right colon & \\
lleocecectomy & 6 \\
Diverticulectomy & 1 \\
Left colon & \\
One-stage resection and anastomosis & 2 \\
Diverticulectomy & 1 \\
\hline
\end{tabular}


Table 6. Number of diverticula

\begin{tabular}{lcc}
\hline No. of diverticula & Right colon $(\mathrm{n}=56)$ & Left colon $(\mathrm{n}=8)$ \\
\hline 1 & $10(17.8)$ & $2(25.0)$ \\
$2-5$ & $21(37.5)$ & $2(25.0)$ \\
$\geq 6$ & $25(44.6)$ & $4(50.0)$ \\
\hline
\end{tabular}

$P=1.000$

Two patients initiated conservative treatments at the time of admission, but were unresponsive to those treatments; they were treated with surgery. The 2 patients presented with abdominal pain associated with abdominal rigidity at the time of admission, but in CT performed at the time of admission, perforation, abscess formation, or findings other complications were not clear. Their symptoms were not improved by conservative treatment after admission. In one $\mathrm{RD}$ patient, abscess formation was detected by repeated CT on hospital day 4, and an ileocecectomy was performed. In one LD patient, peritonitis associated with perforation was detected by repeated CT hospital day 2 , and a diverticulectomy was performed.

\section{Surgical treatments}

In $\mathrm{RD}$, surgical treatments were performed on 7 patients. Among them, a diverticulectomy was performed on 1 patient with repeated recurrence of a solitary diverticulum in the cecum, and ileocecectomies were performed on the remaining 6 patients. In LD, surgical treatments were performed on 3 patients. A diverticulectomy was performed on 1 patient who failed to improve when only conservative treatments were used and who had progressed to peritonitis, and a one-stage partial resection was performed on the remaining 2 patients (Table 5).

Complications did not develop in patients who underwent surgery for RD. Nonetheless, one patient received a diverticulectomy for left colonic diverticulitis in which an enterocutaneous fistula developed, and a partial resection was performed.

\section{Follow-up observation after discharge}

Among the 96 patients, follow-up observation was performed on 71 patients after discharge at outpatient clinics. Among them, colonoscopy was performed on 49 patients, and a barium enema was performed on 22 patients. Among the 71 patients, 7 were treated surgically, and colonoscopy was performed on all of them. On colonoscopic examination of these patients, no residual diverticula were detected. Excluding 7 patients who underwent surgical treatments, in 6 patients among 42 patients, a colonoscopic examination was performed and in 1 patient among 22 patients a barium enema was performed; no diverticula were detected. The numbers of diverticula in the $57 \mathrm{pa}-$ tients whose diverticula were detected by colonoscopic examination or barium enema and the 7 patients whose diverticula were confirmed in surgical resection tissues, were compared, and no clear difference between the right colon and the left colon was detected $(\mathrm{P}=1.000)$ (Table 6$)$.

\section{DISCUSSION}

A colonic diverticulum is a small cyst abnormally protruded from the colon wall, and it is classified as a true diverticulum or a false diverticulum depending on whether it protrudes into all layer or just submucosal tissues [10]. A true diverticulim is a congenital diverticulim in many cases, and it is a protrusion of the entire layer of the colon. A false diverticulim is an acquired one in many cases, and it is the protrusion of the mucosa or submucosal tissues between the muscle layers of a colon weakened due to degenerative changes with aging [7].

Left colonic diverticula, which are prevalent in Caucasians, are primarily false diverticula, rare before the age of 30 years and multicentric in many cases, and their incidence increases with aging $[11,12]$. On the other hand, right colonic diverticula, which are prevalent in Asians, have been reported to be true diverticula; $80 \%$ of the diverticula are solitary, they occur frequently in relatively young age groups, and age is not associated with the incidence $[12,13]$. In other words, in Caucasians, due to the interaction of complex acquired factors such as diet habits, constipation, elevation of the internal pressure of the colon, abnormality of the movement of the intestine, irritable bowel syndrome, etc., false diverticula composed of primarily the submucosal layer are abundant in left colons with a narrow lumen, particularly, in the sigmoid colon. In Asians, because of the congenital weakness of the intestinal wall, true diverticula are abundant, particularly in the right colon [7].

In the West, diverticular diseases are very common. They have been reported to occur up to the age of 45 years and to occur in approximately $5 \%$ to $10 \%$ of the populations; after age 85 , they occur in up to $80 \%$ of the population [14]. On the other hand, in Korea, the incidence of colonic diverticula is low. However, recently, the annual incidence of diverticula has been rise rapidly [4].

Diverticulitis is the representative disease in the diverticula. Feces enter the diverticula and form fecaliths that induce an erosion of the diverticular mucosa. It becomes severe while inflammation progresses and spreads to adjacent tissues. In the West, symptomatic diverticulitis has been reported to account for approximately $20 \%$ of all diverticulitis cases, and cases requiring surgical treatments reach $15-24 \%[15,16]$. In Korea, diverticulitis has been reported to occur in approximately $1.8 \%$ of all diverticula [2]. A study conducted on surgical patients reported that diverticulitis occurred in $28.6 \%$ of all diverticulosis cases [17]. In the West, it has been reported to develop preferentially in women, and the incidence does not vary with gender [18-20]. In contrast, in Korea, different from the West, it has been reported to occur preferentially in males $[6,21]$. Examining the age for onset of diverticulitis in our study, the 
mean age of RD patients was 39.5 years, and the mean age of LD patients was 53.9 years. With aging, the incidence of LD was shown to increase. Fifty-eight patients were males, and 38 were females, which was not greatly different from previous Korean reports in which diverticulitis occurred more frequent in males. In Korea, $\mathrm{RD}$ has been reported to be more common than LD [22-24]. In our study, similarly, it was 8.6:1, and in comparison with $\mathrm{RD}, \mathrm{LD}$ was less frequent.

The clinical features of RD have been reported to be similar to those of acute appendicitis. It is very difficult to distinguish them, and it has been misdiagnosed as acute appendicitis prior to surgery in many cases [7]. In our study, similarly, among 86 patients diagnosed as having right diverticulitis, many patients were diagnosed as having diverticulitis because of imaging tests performed for suspicious appendicitis at the initial diagnosis. Recently, the misdiagnosis rate appears to have been decreased greatly with the wide application of abdominal CT.

In Korea, RD shows better clinical outcomes. In contrast, in the West, $\mathrm{RD}$ shows a more severe course, and complications are more prevalent. One of its major causes for this has been suggested to be diverticulitis that develops in an area where it does not normally occur is overlooked,: thus, its diagnosis is delayed [16]. However, in our study, the interval from the onset of abdominal pain to hospital visit for RD patients was an average 2.5 days, and that for the $\mathrm{LD}$ patients was an average 2.1 days, being somewhat shorter in $\mathrm{LD}$ patients.

The incidence of complications requiring surgery was higher in LD patients, which may be due to right diverticulum frequently being true so that the entire layer of the colon is protruded. On the other hand, in LD, the lumen of the left colon is relatively narrow, and false diverticula protruding between muscle layers weakened due to degenerative changes are abundant. Thus, LD is associated with relatively more perforations, and the number of patients requiring surgical treatments is higher than it is for RD. According to a study reported by Kim et al. [23], complications (particularly perforation) were more prevalent in LD than in RD. In our study, similarly, the incidence of complications requiring surgery was significantly higher in $\mathrm{LD}$ patients than in $\mathrm{RD}$ patients.

In Korea, the incidence of left colonic diverticulitis is low, and it occurs in old patients in comparison with right colonic diverticulitis. The incidence of complications in left colonic diverticulitis is high, and particularly, the possibility of the development of peritonitis associated with perforation is high: thus, the frequency of surgery is high. Because of the aging of the population and the westernization of diets in Korea recently, the incidence of left colonic diverticulitis is on the rise. Therefore, for patients presenting with lower left abdominal pain, aggressive tests for diverticulitis and treatments are thought to be required.

\section{CONFLICT OF INTEREST}

No potential conflict of interest relevant to this article was reported.

\section{REFERENCES}

1. Kim KY, Cha KH, Lee YH, Yoo KS. Surgically experienced diverticular disease of the colon. J Korean Soc Coloproctol 1986;2:31-7.

2. Kim JS, Cha SG, Kim YT, Yoon YB, Song IS, Choi KW, et al. The prevalence and clinical features of diverticular disease of the colon. Korean J Gastroenterol 1993;25:305-14.

3. Sugihara K, Muto T, Morioka Y, Asano A, Yamamoto T. Diverticular disease of the colon in Japan. A review of 615 cases. Dis Colon Rectum 1984;27:531-7.

4. Choi CS, Cho EY, Kweon JH, Lim PS, No HJ, Kim KH, et al. The prevalence and clinical features of colonic diverticulosis diagnosed with colonscopy. Korean J Gastrointest Endosc 2007;35:146-51.

5. Connell AM. Pathogenesis of diverticular disease of the colon. Adv Intern Med 1977;22:377-95.

6. Kim KH, Kim YB, Kang JK, Kim SJ. A clinical study of diverticulosis of the colon. J Korean Med Assoc 1986;29:63-8.

7. Wagner DE, Zollinger RW. Diverticulitis of the cecum and ascending colon. Arch Surg 1961;83:436-43.

8. Parks TG. The clinical significance of diverticular disease of the colon. Practitioner 1982;226:643-54.

9. Roberts P, Abel M, Rosen L, Cirocco W, Fleshman J, Leff E, et al. Practice parameters for sigmoid diverticulitis. The Standards Task Force American Society of Colon and Rectal Surgeons. Dis Colon Rectum 1995;38:125-32.

10. Morson BC. Pathology of diverticular disease of the colon. Clin Gastroenterol 1975;4:37-52.

11. Hackford AW, Schoetz DJ Jr, Coller JA, Veidenheimer MC. Surgical management of complicated diverticulitis: the Lahey Clinic experience, 1967 to 1982. Dis Colon Rectum 1985;28:317-21.

12. Harada RN, Whelan TJ Jr. Surgical management of cecal diverticulitis. Am J Surg 1993;166:666-9.

13. Mariani G, Tedoli M, Dina R, Giacomini I. Solitary diverticulum of the cecum and right colon: report of six cases. Dis Colon Rectum 1987;30:626-9.

14. Rodkey GV, Welch CE. Diverticulitis of the colon: evolution in concept and therapy. Surg Clin North Am 1965;45:1231-43.

15. Ferzoco LB, Raptopoulos V, Silen W. Acute diverticulitis. N Engl J Med 1998;338:1521-6.

16. Anderson L. Acute diverticulitis of the cecum: study of 99 surgical cases. Surgery 1947;22:479-88.

17. Yoon DS, Cheon JD, Cho JW, Kim SI, Park CH, Park CJ, et al. A clinical review of colonic diverticulosis. Korean J Gastroenterol 1992;24:767-73.

18. Parks TG. Natural history of diverticular disease of the colon: a review of 521 cases. Br Med J 1969;4:639-42.

19. Levien DH, Mazier WP, Surrell JA, Raiman PJ. Safe resection for 
diverticular disease of the colon. Dis Colon Rectum 1989;32:30-2.

20. Munson KD, Hensien MA, Jacob LN, Robinson AM, Liston WA. Diverticulitis: a comprehensive follow-up. Dis Colon Rectum 1996;39:318-22.

21. Kwon SU, Choi ST, Choi JS, Lee HJ, Park CW, Jang BI, et al. Endoscopic diagnosis of right-sided colonic diverticulitis. Korean J Gastrointest Endosc 2000;21:704-9.

22. Kim KY, Kim IK, Jung SW, Park KH, Park YJ. Analysis on the surgical treatment of colonic diverticulitis. J Korean Surg Soc 2007;73:36-41.

23. Kim HU, Kim YH, Choe WH, Kim JH, Youk CM, Lee JU, et al. Clinical characteristics of colonic diverticulitis in Koreans. Korean J Gastroenterol 2003;42:363-8.

24. Lee HC, Jeon SW, Kim SY, Kim DJ, Lee WS, Lee JY, et al. Clinical characteristics of right versus left colonic diverticulitis. Korean J Med 2008;75:533-8. 